\title{
Rabid or good neighbors?
}

Great Eastern University, a state-supported college, shared one of its buildings with the State Rabies Diagnostic Laboratory, an agency of the state's Department of Health. The rabies laboratory was near the school's laboratory animal facility, but it had no direct affiliation and shared no work areas with the university. The rabies lab brought dead animals or animal parts to its facility in order to remove tissues for subsequent rabies tests. Recently, some people had begun trapping bats in their own homes and bringing the live bats to the diagnostic lab for rabies testing. There they would be euthanized and tested for rabies.

Great Eastern and its IACUC were totally unaware of the details of the lab's activities until an IACUC protocol was sent to the university from a member of the rabies laboratory. The protocol clearly explained how the live bats were handled and then euthanized at the lab. It also stated that the Department of Health's safety committee had reviewed and approved the procedures and that now they wanted the Great Eastern IACUC to approve the procedures because they were working with live animals covered by the Animal Welfare Act.

For his part, the Great Eastern IACUC's chairman, Dr. Larry Covelli, wanted nothing to do with this protocol, because it came from a state entity that was not part of the university and was submitted by a person who was not part of the university. As Covelli explained it to the IACUC, "the Department of Health, the police and even some private veterinarians euthanize animals for rabies examinations all the time. They don't have IACUCs. The diagnostic lab has been euthanizing live bats for months, and now, out of the blue, they send us a protocol to review because we're the only state institution with an IACUC. Somebody must have told them to get an IACUC approval and we're the easiest way to do that. But I think we should stay away from this. As far as I'm concerned, these are 'private' animals being brought to the diagnostic lab for a rabies test. It has nothing to do with us, and even if the lab needs some sort of IACUC approval, I see lots of aggravation if we're the ones to give it. Just because we're in the same building and our animal facility is near the diagnostic lab doesn't mean that we're obligated to review their protocols."

Is Covelli right, or should Great Eastern University review the State Rabies Diagnostic Laboratory's protocol? Does the laboratory even need IACUC approval for euthanizing bats that might be rabid?

\section{RESPONSE}

\section{Complex circumstances}

\section{Susan R. Blumenthal, PhD}

At first glance, the issues facing the Great Eastern IACUC seem straightforward, but on closer inspection, they are even more complex than Covelli has presented to the IACUC. The arguments presented by Covelli regarding the separation of the two institutions appear to be valid reasons for the Great Eastern IACUC to decline review of the protocol. The Animal Welfare Act Regulations (9 CFR C.2.30(a) Registration Requirements and Procedures ${ }^{1}$ ) state that "(1) Except as provided in paragraph (a)(2) of this section, where a school or department of a university... intends to use live animals for research, tests, experiments, or teaching, the university... rather than the school or department will be considered the research facility and will be required to register with the Secretary.... (2) In any situation in which a school or department of a university... demonstrates to the Secretary that it is a separate legal entity and its operations and administration are independent of those of the university..., the school or department will be registered rather than the university... (3) A subsidiary of a business corporation, rather than the parent corporation, will be registered as a research facility unless the subsidiary is under [the] direct control of the parent corporation...". The diagnostic laboratory, although it is a state-funded entity, is an agency of the state Department of Health and, as such, appears to have separate financial support from that provided to Great Eastern by the state. In addition, the diagnostic laboratory has separate administration from Great Eastern and appears to be separated from the university physically, as they do not share the physical space occupied by the diagnostic laboratory.

On the other hand, many state diagnostic laboratories provide training to university graduate and professional students as part of their formal educational coursework and function as university departments as well as parts of the state's Department of Public Health or Agriculture. If this is the case, then the laboratory would not be a separate entity but would be considered part of the university, and the Great Eastern IACUC would be responsible for the activities of the laboratory. There is no evidence that the State Rabies Diagnostic Laboratory in this case functions in this manner, but this is one of several issues that the IACUC should clarify before declining to review the protocol.

Covelli's other arguments regarding the protocol raise issues that are more complex. Most certainly the level of "aggravation" associated with its review is not adequate or appropriate justification for the IACUC to refuse responsibility for a protocol. Likewise, his argument that other agencies or persons "euthanize animals for rabies examinations all the time" without IACUC oversight has no bearing on whether or not this IACUC should or should not review the protocol. The fact that state law may allow for euthanasia and rabies testing of animals by 